\title{
ARTIGO
}

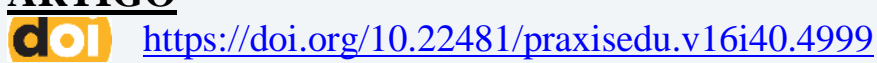

\section{ESTIMULAÇÃO PRECOCE: O CASO DE UMA CRIANÇA COM SEQUÊNCIA DE PIERRE ROBIN}

\author{
EARLY STIMULATION: THE CASE OF A CHILD WITH SEQUENCE OF PIERRE \\ ROBIN
}

\section{ESTIMULACIÓN PRECOZ: EL CASO DE UN NIÑO CON SECUENCIA DE PIERRE ROBIN}

\author{
Rosely Vieira dos Santos Martins \\ Universidade Federal de Mato Grosso do Sul - Brasil \\ Giovani Ferreira Bezerra \\ Universidade Federal da Grande Dourados - Brasil
}

\begin{abstract}
Resumo: Este estudo analisa o processo de estimulação precoce de uma criança com necessidades educacionais especiais (NEE), em virtude de Sequência de Pierre Robin (SPR), atendida por uma instituição privado-filantrópica de Educação Especial, relacionando os contextos familiar e especializado. Utilizou-se a abordagem qualitativa, com análises descritivas, empregando-se como procedimentos técnicos as pesquisas bibliográfica e de campo para coleta de dados, por meio de estudo de caso. Pelas análises, pôde-se perceber que, desde a chegada da criança com SPR à instituição, em 2015, até o ano de realização da pesquisa, em 2018, houve progressos no seu desenvolvimento, também possibilitados pela participação da mãe, apesar das dificuldades de trabalho da última professora, que relatou falta de experiências com tal modalidade de intervenção pedagógica especializada. Assim, defende-se a necessidade de apoio institucional para que não haja ruptura entre as práticas desenvolvidas pelos docentes, de modo a se garantir o desenvolvimento integral da criança e articulação entre todos os agentes e serviços envolvidos com a estimulação precoce.
\end{abstract}

Palavras chave: Estimulação precoce. Necessidades Educacionais Especiais. Prática Pedagógica.

\begin{abstract}
This study analyzes the process of early stimulation of a child with Special Educational Needs (SEN), due to Pierre Robin Sequence (PRS), attended by a private-philanthropic institution of Special Education, relating the family and specialized contexts. The qualitative approach was used, with descriptive analyzes, using bibliographic and field research for data collection as technical procedures, through a case study. From the analyzes, it was possible to notice that, since the arrival of the child with PRS at the institution, in 2015, until the year of the research, in 2018, there was progress in its development, also made possible by the mother's participation, despite the difficulties of work of the last teacher, who reported a lack of experience with this type of specialized pedagogical intervention. Thus, the need for institutional support is defended so that there is no rupture between the practices developed by the teachers, in order to guarantee the integral development of the child and articulation between all agents and services involved with early stimulation.
\end{abstract}

Keywords: Early Stimulation. Special Educational Needs. Pedagogical Practice. 
Resumen: Este estudio analiza el proceso de estimulación temprana de un niño con Necesidades Educativas Especiales (NEE), debido a la Secuencia de Pierre Robin (SPR), a la que asiste una institución filantrópica privada de Educación Especial, que relaciona los contextos familiares y especializados. Se utilizó el enfoque cualitativo, con análisis descriptivos, utilizando investigación bibliográfica y de campo para la recopilación de datos como procedimientos técnicos, a través de un estudio de caso. A partir de los análisis, fue posible notar que, desde la llegada del niño con SPR a la institución, en 2015, hasta el año de la investigación, en 2018, hubo progreso en su desarrollo, también posible gracias a la participación de la madre, a pesar de las dificultades de trabajo del último profesor, quien informó de una falta de experiencia con este tipo de intervención pedagógica especializada. Así, se defiende la necesidad de apoyo institucional para que no haya ruptura entre las prácticas desarrolladas por los docentes, a fin de garantizar el desarrollo integral del niño y la articulación entre todos los agentes y servicios involucrados en la estimulación temprana.

Palabras clave: Estimulación precoz. Necesidades Educativas Especiales. Práctica Pedagógica.

\section{Introdução}

Este artigo tem o intuito de problematizar como ocorria o processo de estimulação precoce de uma criança com Necessidades Educacionais Especiais (NEE), em virtude de uma condição ontogênica rara, a Sequência de Pierre Robin (SPR), nos contextos familiar e especializado, em uma cidade de pequeno porte localizada ao sul de Mato Grosso do Sul, cujo nome se omite para garantir o sigilo ético da pesquisa. Segundo Glat e Pletsch (2012, p. 22),

O conceito de necessidade educacional especial está intimamente relacionado à interação do aluno com a proposta ou a realidade educativa com a qual ele se depara. Necessidade educacional especial não é uma característica homogênea fixa de um grupo etiológico, também supostamente homogêneo; é uma condição individual e específica que se manifesta a partir da experiência de escolarização a que o aluno é submetido.

De início, vale ressaltar que se adota, aqui, o termo estimulação precoce, pois foi a terminologia encontrada nos documentos oficiais em contexto brasileiro. Há relevância de se discutir sobre essa temática, ainda pouco abordada cientificamente no Brasil (CARDOSO; FERNANDES PROCÓPIO; PROCÓPIO, 2017; SILVA et al., 2017), pois é na infância que a criança está se desenvolvendo, e os estímulos que lhe forem propostos sistematicamente serão de suma importância para suas aprendizagens fundamentais. Com os estudos realizados, foi possível depreender que o termo estimulação precoce, desde seu surgimento nos Estados Unidos, tem sido alvo de críticas, bem como de propostas para modificações ou de atualizações 
semânticas, ao longo dos anos. De acordo com Nascimento et al. (2018, p. 432),

O termo Estimulação Precoce (EP) é mais antigo e precede o termo Intervenção Precoce (IP), sendo que o conceito do primeiro se restringe ao trabalho em competências específicas, como motoras e sensoriais, com o objetivo específico de corrigir ou remediar pontualmente falhas nessas áreas de domínio. Já o termo IP engloba um conceito mais amplo, o qual, além do conjunto de intervenções direcionadas diretamente à criança, abrange ações direcionadas à família e ao contexto, em busca de melhores respostas da criança em questão às necessidades que apresente, sejam elas transitórias ou permanentes.

Com vistas a melhor compreender tal prática especializada e suas implicações pedagógicas, o interesse por pesquisar um programa de estimulação precoce foi surgindo, pela primeira autora deste artigo, a partir das suas experiências vivenciadas durante o estágio remunerado, como acadêmica do curso de Pedagogia. Tal estágio se iniciou no dia 21 de agosto de 2015 e se estendeu até o final do ano de 2018, em uma instituição privadofilantrópica de Educação Especial do citado município, mais especificamente em uma sala frequentada pela turma de educação precoce, conforme a nomenclatura dada pela instituição.

O objetivo geral da pesquisa foi, então, desdobrado em três outros, específicos, a saber: a) conhecer e analisar a prática pedagógica da professora especializada e suas concepções no que tangia ao processo de estimulação precoce da criança com SPR que necessitava desse trabalho; b) conhecer e analisar as concepções e formas de atuação dos familiares e ou responsáveis acerca desse mesmo processo de estimulação; c) investigar como acontecia o relacionamento entre professora/família no processo de estimulação precoce da criança com SPR. Dados esses objetivos, optou-se, metodologicamente, por um estudo de caso. Como instrumento para coleta de dados, foram utilizadas entrevistas semiestruturadas e observação participante em campo. Os resultados desse trabalho, com a discussão sobre a temática e detalhamento metodológico, são apresentados em seguida.

\section{Estimulação precoce e o desenvolvimento da criança com NEE}

A fim de uma breve contextualização, o termo estimulação precoce sofreu várias alterações em sua nomenclatura, pois não há um consenso sobre seu uso quanto à literatura especializada, havendo vários significados para sua definição. Segundo diretrizes oficiais brasileiras, publicadas ainda na década de 1990,

Na prática educacional, vários termos têm sido utilizados para designar o 
programa de estimulação precoce, destinado a atender a criança portadora ${ }^{1}$ de necessidades especiais de zero a três anos de idade.

Mais recentemente alguns grupos de profissionais passaram a adotar a expressão "estimulação essencial" para substituir "estimulação precoce", como uma tentativa de designar, com clareza, o significado dessa intervenção especial.

A expressão "estimulação precoce" é derivada da tradução dos termos correlatos do espanhol ("estimulación temprana" e "estimulación precoz") e também em inglês ("early stimulation" ou "early intervention") (BRASIL, 1995, p.11).

Em que pesem tais ponderações terminológicas, em 2016, pelo Ministério da Saúde, foi divulgado o documento Diretrizes de Estimulação Precoce: crianças de zero a 3 anos com atraso no desenvolvimento neuropsicomotor, elaborado por profissionais da saúde devido ao aumento de casos de microcefalia em função de infecção pelo vírus zika no Brasil. Tais documentos e suas orientações têm direcionado as equipes de multiprofissionais em seus trabalhos no processo de estimulação precoce de crianças com NEE que necessitem dessa intervenção especializada.

Vale considerar que o objetivo da estimulação precoce é o desenvolvimento integral do indivíduo com comprometimentos neuropsicomotores em todos seus aspectos, não só da pessoa com Deficiência Intelectual e Múltipla, para que desenvolva ao máximo suas habilidades, com isso conquistando sua autonomia. De acordo com Borges (2016, p.38), “[...] a estimulação precoce como forma preventiva tem como objetivo principal fazer com que a criança desenvolva potencialmente suas capacidades de desenvolvimento, possibilitando a mais completa integração com a família, a escola e a sociedade".

Assim, de modo adequado, essa intervenção tem que ser realizada o quanto antes, pois, se iniciada antecipadamente, mais benefícios serão alcançados no desenvolvimento integral do sujeito. Segundo o manual Diretrizes Educacionais sobre Estimulação Precoce,

[...] a carência, a inadequação, inclusive a sobrecarga de estimulação nos primeiros anos de vida, diminuem o ritmo natural do processo evolutivo infantil, aumentando também o distanciamento dos padrões do desenvolvimento físico, sensório-perceptivo, motor, socioafetivo, cognitivo e da linguagem. (BRASIL, 1995, p. 7).

A princípio, tais estudos sobre a estimulação precoce surgiram nos Estados Unidos, na década de 1960. Inicialmente, seu intuito era de compensar a defasagem no desenvolvimento das crianças de famílias pobres que não tinham condições

\footnotetext{
${ }^{1}$ Nomenclatura usada na época. Recomenda-se, atualmente, o não emprego do termo portador no caso de deficiência ou necessidades educacionais especiais.
} 
socioeconômicas satisfatórias e eram vítimas da chamada carência afetiva materna. De acordo com Borges (2016, p. 38), “Os estudos sobre estimulação precoce iniciaram nos EUA em 1960 e tinham como fundamentos básicos: a carência afetiva, a privação cultural na infância e os estudos da teoria de Piaget”. Com o aprimoramento nas pesquisas científicas sobre o programa de estimulação precoce, teve-se uma nova visão de seu conceito, na perspectiva da contribuição para o desenvolvimento completo e contextualizado da criança. Segundo Nascimento et al. (2018, p.433),

Nas últimas décadas esses programas passaram por mudanças notáveis, principalmente em relação a dois aspectos: ao papel das famílias, que agora passam a ter um papel essencial e não mais secundário; e à esfera de atuação, estendendo-se aos campos da saúde, social e educativo.

Ao longo dos anos, os programas de estimulação precoce se desenvolveram também em outros países, dentre eles: Argentina, entre 1960/1970; Portugal, na década de 1970. Na Espanha, começou a se desenvolver por volta de 1979, a partir da Primeira Conferência Internacional sobre Estimulação Precoce (TERZAGHI; CORIAT, 2000; BORGES, 2016). Ademais, a Declaração de Salamanca (UNESCO, 1994) contribuiu para que surgissem, na década de 1990, as primeiras leis sobre a estimulação precoce (BORGES, 2016). A partir desse momento, “[...] surge no Brasil o primeiro documento que abordou a estimulação precoce denominado de Diretrizes Educacionais sobre Estimulação Precoce (1995), elaborado pela Secretaria de Educação Especial/MEC, que orientou a prática desse programa naquele momento [...]” (BORGES, 2016, p.44). O documento citado definiu a estimulação precoce como:

Conjunto dinâmico de atividades e de recursos humanos e ambientais incentivadores que são destinados a proporcionar à criança, nos seus primeiros anos de vida, experiências significativas para alcançar pleno desenvolvimento no seu processo evolutivo (BRASIL, 1995, p.11, grifo no original).

Assim, a estimulação precoce foi sendo compreendida como um programa multidisciplinar, envolvendo profissionais de diversas áreas, como fonoaudiologia, fisioterapia, psicologia, terapia ocupacional, assistência social e Educação Especial, com o intuito de prevenir e ou mitigar possíveis déficits e limitações no desenvolvimento neuropsicomotor da criança, pois o quanto antes essa intervenção for buscada, maiores serão suas conquistas e aquisições pessoais (GOLLO; GRAVE, 2015). E, apesar de críticas, o termo acabou se tornando recorrente no país e endossado pelas publicações governamentais, porquanto: 
Embora o termo "precoce" possa suscitar alguma dúvida quanto ao seu significado etimológico, ele preserva em sua essência, a natureza preventiva que é o objetivo fundamental desse programa. O sentido de "precoce", neste caso, adjetiva ações suficientemente antecipadas, tendentes a evitar, atenuar ou compensar a deficiência de que a criança possa ser portadora e/ou suas consequências ${ }^{2}$. Por outro lado, a expressão "estimulação precoce" já é consagrada pelo uso, tanto em nosso meio como internacionalmente, para referir-se ao sentido que se lhe atribui em tais programas. [...]. Pelo exposto, adota-se a expressão "ESTIMULAÇÃO PRECOCE", considerando-a como a mais adequada para esses fins. (BRASIL, 1995, p.11).

O desenvolvimento integral da criança em todos seus aspectos vem atrelado, nesses programas, aos estímulos que lhe são ofertados individualmente, tanto no âmbito familiar quanto no institucional e pedagógico. No dizer de Costa (2013, p. 19), “[...] os programas funcionam por meio de atendimentos individualizados considerando a prioridade de maximizar o desenvolvimento da criança [...]”. Nesse contexto, a Educação Especial, aliada a outras áreas, tem papel destacado. Como já afirmava o Referencial Curricular Nacional para a Educação Infantil: estratégias e orientações para a educação de crianças com necessidades educacionais especiais, “A educação especial, no entanto, antes mesmo da promulgação da LDB/96, já entendia que o atendimento especializado oferecido a crianças com necessidades especiais era de competência da área educacional, definindo esse atendimento como Estimulação Precoce” (BRASIL, 2000, n. p.).

Essa interface dos programas especializados com a práxis pedagógica é fundamental, porquanto, na Educação Infantil, a criança com NEE está mais propensa a responder positivamente aos estímulos que lhe são propostos na rotina do dia a dia, favorecendo a ampliação de suas habilidades linguísticas, cognitivas, motoras etc. De acordo com Borges (2016, p. 54-55),

Na Educação Infantil assim como na estimulação precoce o objetivo principal é fomentar o desenvolvimento global da criança, apregoando a importância de estímulos para o desenvolvimento infantil. A estimulação que a criança recebe desde que nasce e se estende aos primeiros anos de vida é indispensável para o seu desenvolvimento, pois lhe permite atingir novas fases, proporcionando que ela experimente e conviva com pessoas, gerando experiências de aprendizagem enriquecedoras.

Diante do exposto, fica patente que, quando se pensa na abordagem da estimulação precoce para as crianças com NEE, não se pode desvinculá-la da Educação Infantil enquanto

\footnotetext{
${ }^{2}$ As citações foram atualizadas para nova reforma ortográfica.
} 
etapa educacional. De acordo com o mesmo Referencial Curricular Nacional para a Educação Infantil (BRASIL, 2000, p. 12), “A educação especial articula-se com a educação infantil no seu objetivo de garantir oportunidades sócio-educacionais à criança, promovendo o seu desenvolvimento e aprendizagem, ampliando dessa forma, suas experiências, conhecimento e participação social”.

Desse modo, a estimulação precoce não deve ter um olhar só clínico-terapêutico ou meramente assistencialista, mas todos os serviços prestados à criança com NEE precisam estar articulados entre si para não perder de vista sua relação constitutiva com a dimensão pedagógica e com os vários contextos e agentes implicados. As práticas pedagógicas do docente, sobretudo em contextos especializados de atenção à primeira infância, precisam ser, portanto, fundamentadas pelos documentos oficiais, proposições teórico-metodológicas acumuladas nas pesquisas científicas sobre o assunto e demais diretrizes sobre essa prática de estimulação. Afinal, nesse período de vida a criança apresenta maior plasticidade na construção de sua identidade e de novas aprendizagens, necessitando, para isso, de apoios, ações educacionais e suportes específicos, conforme suas particularidades ontogenéticas.

\section{Metodologia}

No decorrer de todo o percurso metodológico, houve a realização de estudos bibliográficos, como de praxe na investigação científica. Em seus fundamentos, a pesquisa baseou-se na abordagem qualitativa, sendo descritiva no tocante aos seus objetivos, com o intuito de compreender como ocorria o processo de estimulação precoce de uma criança com SPR nos contextos familiar e especializado. Segundo Gil (2008, p.42), “As pesquisas descritivas têm como objetivo primordial a descrição das características de determinada população ou fenômeno ou, então, o estabelecimento de relações entre variáveis. [...]”. Do ponto de vista dos procedimentos técnicos, optou-se por um estudo de caso, pois este permitia análise aprofundada e particularizada em relação à temática. Para Gil (2008, p. 54),

O estudo de caso é uma modalidade de pesquisa amplamente utilizada nas ciências biomédicas e sociais. Consiste no estudo profundo e exaustivo de um ou poucos objetos, de maneira que permita seu amplo e detalhado conhecimento, tarefa praticamente impossível mediante outros delineamentos já considerados.

Bogdan e Biklen (1994, p. 89) também discorrem sobre o estudo de caso, citando que: "O estudo de caso consiste na observação detalhada de um contexto, ou indivíduo, de uma 
única fonte de documentos ou de acontecimento específico". Para coletar os dados em campo, foram realizados trinta dias de observação participante na instituição especializada frequentada pela criança, onde a primeira autora deste texto também atuava como estagiária, no já citado município, além da realização das entrevistas semiestruturadas com as pessoas que mais podiam fornecer informações sobre o caso, conforme se descreve nos subitens seguintes.

\subsection{Sujeito-alvo da pesquisa}

O sujeito-alvo da pesquisa foi uma criança do sexo feminino, com essa condição ontogênica rara, denominada Sequência de Pierre Robin (SPR), que comprometia seu desenvolvimento motor e a oralidade. De fato, "A SPR é uma anomalia congénita caraterizada pela presença de uma combinação de hipoplasia mandibular (micrognatia), glossoptose (retrusão da língua para a via faríngea) levando a obstrução das vias aéreas [...], e frequentemente a fenda palatina [...]" (MACHACÁS, 2015, p. 1). Ainda conforme o mesmo autor explica, "No geral, a incidência da SPR é baixa: 1 em 8.500 a 20.000 nascimentos na população geral. A prevalência é igual em ambos os sexos [...]” (MACHACÁS, 2015, p. 2). Inicialmente, tal condição, de acordo com Sato et al. (2007, p.161-162),

[...] era conhecida como Síndrome de Pierre Robin, entretanto, o termo síndrome passou a ser apenas utilizado para alterações na morfogênese com presença simultânea de múltiplas anormalidades causadas por uma única etiologia. Sendo assim, o termo sequência foi introduzido para incluir qualquer condição que envolva uma série de anormalidades causadas por uma cascata de eventos iniciados por uma única malformação. Dessa forma, a então conhecida Síndrome de Pierre Rubin [sic] passou a ser denominada como um complexo sintomático, não-específico, que pode ocorrer em várias situações isoladamente, em associação a alguma síndrome conhecida ou em associação com outros defeitos de desenvolvimento, que juntos não correspondem a uma síndrome específica. A literatura descreve a Sequência de Pierre Rubin (SPR) como uma tríade a anomalias caracterizadas por micrognatia ${ }^{3}$, glossoptose $e^{4}$ fissura de palato.

No momento da realização do estudo, a criança com SPR tinha três anos de idade e estava matriculada, no período matutino, na turma de educação precoce da instituição privado-filantrópica de Educação Especial onde se deu a pesquisa.

\footnotetext{
${ }^{3}$ Micrognatia caracteriza-se pela deformidade da mandíbula inferior, sendo menor que o normal.

${ }^{4}$ Glossoptose é o deslocamento da língua para trás, provocando obstrução da faringe.
} 


\subsection{Processo de observação}

A criança foi observada durante trinta dias consecutivos, sendo analisados, neste momento propício, seu comportamento na realização das atividades pedagógicas e sua interação com a professora e os demais sujeitos da sala, bem como as condições físicas e organizacionais deste espaço. A observação se iniciou no dia 01 de abril, findando no dia 30 do referido mês, no ano de 2018. A observação foi do tipo participante pelo fato de a primeira autora deste trabalho ser estagiária remunerada na instituição, o que possibilitou uma maior proximidade e envolvimento com a realidade pesquisada. Segundo Mónico et al. (2017, p. 726), “O método da Observação Participante é especialmente apropriado para estudos exploratórios, estudos descritivos e estudos que visam a generalização de teorias interpretativas". Ainda para os mesmos autores,

Habitualmente recorre-se à Observação Participante com o propósito de elaborar, após cada sessão de observação, descrições "qualitativas", de tipo "narrativo" (i.e., sem recorrer a grelhas de observação estandardizadas), que permitem obter informação relevante para a investigação em causa [...].

$\mathrm{Na}$ designação das Ciências Sociais, o investigador procura tornar-se membro de um grupo, organização ou eventualmente ficar sob estudo. Por estar imerso na progressão dos eventos, o investigador espera encontrar-se numa posição privilegiado [sic] para obter muito mais informações, e um conhecimento profundo do que aquele que seria possível se estive [sic] a observar de fora [...] (MÓNICO et al., 2017, p. 726).

Com base em roteiro prévio, foram priorizados pontos a serem observados como: a organização da sala para estimulação das crianças e os materiais existentes; recursos pedagógicos utilizados pela professora; desenvolvimento das práticas e atividades pedagógicas; dentre outros. As anotações no diário de campo eram feitas após o término do expediente, pois como a pesquisadora estava imersa na situação como estagiária, ficava, também, inviável fazer as anotações imediatamente no local, além do que isso poderia ser desconfortável à professora observada.

\subsection{Sujeitos entrevistados}

As entrevistas foram semiestruturadas, sendo autorizadas pelas pessoas entrevistadas, que assinaram o Termo de Consentimento Livre e Esclarecido (TCLE). Foram todas realizadas no mês de maio de 2018, sendo gravadas e, posteriormente, transcritas para análise. A princípio, o intuito era entrevistar somente a professora do ano de 2018 e a mãe da criança, 
mas, no decorrer do estudo, evidenciou-se que, devido ao fato de essa professora ter iniciado com a turma de estimulação precoce apenas em fevereiro de 2018, fazia-se necessário entrevistar, também, a professora da criança com SPR dos anos anteriores. A profissional foi, então, incluída entre os sujeitos a serem entrevistados, designada como P1, de maneira a se buscar uma compreensão satisfatória da problemática. Como apurado na instituição, P1, estando há quatro anos consecutivos à frente da turma de educação precoce, havia trabalhado com essa criança desde que esta ingressara na instituição, em 2015. Logo, tal professora conhecia a trajetória da criança e tinha informações relevantes para se entender o caso em estudo, em sua processualidade.

Portanto, as pessoas entrevistadas foram: I) duas professoras, sendo que uma trabalhara com a criança com SPR no período de 2015 a 2017, chamada de P1, e a professora que ingressou na turma de educação precoce somente no ano de 2018, designada por P2; II) a mãe da criança (M) sujeito-alvo da pesquisa, representando a dimensão do ambiente familiar. Para manter o anonimato dos sujeitos entrevistados, em virtude de implicações éticas, usamos essas siglas e, para fins de caracterização, identificamos suas respectivas formações e atuações profissionais, no intuito de tornar mais inteligível a discussão do caso.

QUADRO 1: Identificação dos sujeitos entrevistados para o estudo

\begin{tabular}{|c|c|}
\hline Siglas para identificação dos sujeitos & Formação $\begin{array}{c}\text { e atuação dos } \\
\text { sujeitos entrevistados }\end{array}$ \\
\hline $\mathrm{P}_{1}$ & $\begin{array}{l}\text { Professora da educação precoce com } \\
\text { Normal Superior; Pós em Educação } \\
\text { Infantil, Educação Especial e Anos Iniciais. } \\
\text { Atuava há dez anos como docente. }\end{array}$ \\
\hline $\mathrm{P}_{2}$ & $\begin{array}{l}\text { Professora da educação precoce com } \\
\text { Pedagogia, Pós em Educação Infantil e } \\
\text { Neuropedagogia. Atuava há cinco anos } \\
\text { como docente. Em 2018, cursava } \\
\text { especialização em Educação Especial. }\end{array}$ \\
\hline M & $\begin{array}{l}\text { Mãe da criança, do lar, com ensino } \\
\text { fundamental incompleto. }\end{array}$ \\
\hline
\end{tabular}

Fonte: elaboração própria.

Para a realização da entrevista, P1 se deslocou de sua residência até o local onde mora a pesquisadora, aí cedendo seus depoimentos. As entrevistas com P2 e a mãe da criança com SPR foram realizadas em suas respectivas casas, mas P2 solicitou o acesso ao roteiro de questões nove dias antes da entrevista, sendo atendida em sua solicitação. Nas entrevistas 
com as professoras, foram feitas questões referentes a: como era e como avaliavam seu trabalho pedagógico na sala de educação precoce; quais os recursos disponibilizados nessa sala para a estimulação da criança com SPR e como era a interação professora/mãe; interação da criança/demais crianças da sala. Já para a mãe foram feitas, basicamente, perguntas em relação a: como era a interação dela com as professoras da instituição especializada; de que modo se dava sua participação no processo de estimulação da filha com SPR e como percebia os resultados desse processo.

\section{Resultados e discussões}

Com base nos dados coletados pelos procedimentos elencados, foi possível discorrer sobre alguns eixos temáticos emergentes, a partir das questões propostas nos roteiros de entrevistas e dos itens visados no roteiro de observação participante, os quais são apresentados na sequência como subitens deste tópico.

\subsection{A prática pedagógica das professoras e suas concepções sobre o processo de estimulação precoce}

De início, quando questionadas sobre como era o trabalho delas, na sala de educação precoce, as professoras (P1 e P2) deram as seguintes respostas,

Olha, eu trabalhei com a educação precoce por quatro anos, foi um trabalho muito bom. É! Recebi alunos com seis meses. Foi a estimulação de seis meses a quatro anos. Foi um trabalho, assim, muito gratificante, porque são vidas que estão começando ali, né? Então, é tudo através de muita estimulação e muita conversa, muito diálogo com os pais para poder desenvolver um bom trabalho. (P1, grifos nossos).

Então! É meu primeiro ano na sala de estimulação. Eu sempre trabalhei com alfabetização. Então! Assim, é, eu tento fazer o melhor, que para mim é novo, para eles também, por causa da troca de professores, né? Mas eu trabalho bastante a fala, a gente conversa muito com eles, sempre estou instigando, perguntando como que foi em casa, o que fez, da família e seu trabalho. ( $\mathrm{P} 2$, grifos nossos).

Em seus relatos, as professoras P1 e P2 explicitaram valorizar a oralidade, como estratégia metodológica, em suas práticas pedagógicas, no programa de estimulação precoce. Ao dizerem que trabalhavam o desenvolvimento da fala, possibilitavam o desenvolvimento da linguagem, da comunicação na criança, o que está de acordo com Tuleski (2008, p.159): "A linguagem, portanto, é fundamental para o desenvolvimento de todas as demais funções; 
reestrutura o pensamento, conferindo-lhe novas formas e, através do pensamento verbal, transforma todas as outras funções". Bezerra (2017, p. 962) afirma, também, que "A fala, nesse contexto, é o meio inicial e basilar pelo qual sentidos e significados podem ser apropriados, partilhados e (re)construídos por esses sujeitos”. Ainda sobre os primeiros momentos de sua prática pedagógica com a criança com SPR, P1 relatou:

[...] ela nunca tinha saído do convívio da mãe. Assim, depois que ela começou se apegar um pouquinho ao professor e aprendemos também como alimentar ela, aí a gente começou com [a estimulação pedagógica], que era por [recurso] tátil, visual e aí criamos mecanismos onde que ela conseguiu se desenvolver. (P1).

A professora P1 explicitou que, após estabelecer vínculos com a criança, começou a desenvolver propostas para sua estimulação. Seus dizeres reforçam a relevância da afetividade e vínculo professor/aluno nesse período inicial. Segundo o manual Diretrizes de Estimulação Precoce, "A dedicação de afeto, tempo, compreensão e aprovação dos adultos aos seus atos ajudarão a criança a desenvolver a confiança em si mesma e um autoconceito positivo" (BRASIL, 2016, p. 71). Ainda em relação ao trabalho realizado com a criança com SPR, P1 esclareceu que:

Foi um trabalho de equipe, porque naquele tempo a gente podia contar com a fisioterapia e com fonoaudióloga, com a psicóloga; e aí a gente criou um método de trabalho voltado simplesmente para desenvolvimento dela, e, nisso, eu creio que teve bastante resultado. Não era simplesmente só um professor na sala, era uma professora e uma estagiária, onde que ajudava bem mesmo. E esse trabalho creio que deu bastante resultado. (P1, grifos nossos).

Nesse relato, P1 referiu-se às condições de trabalho em momentos anteriores a 2018, quando havia uma articulação com a equipe, envolvendo outros profissionais que atendiam a criança com SPR na instituição. Segundo diretrizes divulgadas pelo governo federal, "A estimulação destas competências [habilidades cognitivas e sociais] envolve variados facilitadores desde a equipe multiprofissional até a família da criança, cujo papel é central em seu desenvolvimento" (BRASIL, 2016, p. 120). Destarte, por suas considerações, percebe-se que $\mathrm{P} 1$, juntamente com os profissionais das demais áreas, desenvolveram um trabalho especializado e articulado de estimulação para essa criança.

Em outras palavras, as práticas relatadas por P1 vão ao encontro das diretrizes oficiais, de acordo com as quais “O trabalho de 'estimulação precoce' deve ser estruturado de forma a prestar atendimento sistemático à criança e a sua família” (BRASIL, 1995, p. 21). Logo, é mister a identificação e atendimento das necessidades específicas da criança com 
algum percurso ontogenético diferenciado, como no caso de SPR, para se deflagrar mediação pedagógica pertinente e planejada. Tais considerações ficam corroboradas neste trecho dito por P1:

A criança [com SPR] chegou com nove meses. Ela estava bem debilitada mesmo! A anemia dela [estava] muito alta e devido à dificuldade que ela tinha para se alimentar, porque ela se alimentava só por sonda. A dificuldade maior era que primeiro suprisse mais a alimentação dela, que ela começasse se alimentar melhor, para a gente começar a fazer um trabalho com ela. (P1).

Como relatado, ao chegar à instituição, a criança, em virtude das complicações ocasionadas pela própria SPR, exigia cuidados muito precisos. Seu estado de saúde era bem delicado, alimentando-se por sonda. Tal fato precisava, portanto, ser considerado como prioridade no programa de atenção especializada. Assim, o cuidado de P1 em relação à alimentação dessa criança foi relevante, pois a professora estava diante de um desafio que precisava ser conhecido e abordado sistematicamente para posteriores avanços em outros domínios do desenvolvimento infantil. De fato, a esse respeito, Sato et al. (2007, p. 163-164, grifos nossos) afirmam que:

A prioridade no tratamento da sequência de Robin deve ser a manutenção da permeabilidade das vias aéreas. Sem o tratamento adequado, a hipóxia crónica com retenção de $\mathrm{CO}_{2}$ e o aumento da resistência vascular pulmonar pode levar à insuficiência cardíaca por doença pulmonar (corpulmonale). Além disso, as crises recorrentes de cianose podem levar a hipóxia cerebral. Nessas situações, a polissonografia também passa a ser importante no diagnóstico dos quadros de apneia. $O$ segundo ponto de cuidado deve ser a dificuldade alimentar, que é de certa forma uma consequência da dificuldade respiratória, sendo frequente a necessidade de alimentação por sonda para alimentação. Cuidado deve ser tomado em relação à alimentação, devido às dificuldades como pouco leite ingerido, alimentação por via oral demorada, fadiga, tosse, engasgos, vómitos e regurgitações. Essas dificuldades podem levar à desnutrição protéico-calórico. Dessa forma, em muitos casos de sequência de Robin, é necessária a instalação de sondas alimentadoras [...].

Em sua fala, P1, de início, não desconsiderou, portanto, tal particularidade sobre a alimentação da criança com SPR, pois essa era a necessidade básica inicial a ser satisfeita. Essas ações docentes estão em consonância com as diretrizes governamentais, porquanto expõem que “[...] a complementação alimentar é necessária e o desenvolvimento de um programa específico de estimulação precoce tende a diminuir consideravelmente tal risco [para as deficiências e suas complicações posteriores]” (BRASIL, 1995, p. 35). Por sua vez, quanto 
ao desenvolvimento das atividades pedagógicas, P2 assim se posicionou:

Então! Como eu disse, eu realizo todas as atividades em grupo; então, o que eu faço? Trabalho com as peças de montar, às vezes lápis de cor. Nas vezes que utilizei lápis de cor, deu um pouco de trabalho porque ela queria tudo para ela, mas, assim, é uma criança que está em fase de aprendizagem. [...]. Eu tento mostrar para ela que nada é só dela, que tem que dividir com os outros, ela chora. [...]. Na parte motora, às vezes, atividades de correr, é atividade de encaixe, coisas assim que eu estou trabalhando agora, por enquanto. (P2).

P2 destacou a prática de trabalho em grupo, estratégia que, também, possibilita o desenvolvimento da linguagem, pela interação entre as crianças. Trata-se de uma iniciativa promissora, visto que "A linguagem desempenha um papel essencial na organização perceptual, na recepção e na estruturação das informações, na aprendizagem enas interações sociais do ser humano" (BRASIL, 2016. p. 69). Além disso, não se descarta, na estimulação precoce, essa forma de organização do atendimento especializado, conquanto "No que se refere ao atendimento em grupo, é aconselhável a formação de grupos pequenos de duas ou três crianças, constituídos com base na idade de desenvolvimento, ou de acordo com a idade cronológica, respeitando-se as características individuais das crianças" (BRASIL, 1995, p. 22).

Porém, mesmo P2 tendo relatado na entrevista que trabalhava frequentemente com tais atividades, durante o período de observação, não foi possível verificar que ela desenvolvesse todas as atividades elencadas. Dessa forma, sua prática pedagógica se limitava principalmente ao cuidar e ao brincar. E, ainda mediante a análise em campo, verificou-se que a instituição especializada, juntamente com seu corpo docente, ainda carecia de subsídios teóricos para elaborar atividades pedagógicas sistematizadas que promovessem o ensino/aprendizagem de sujeitos que demandavam atendimento tão especializado, como no caso em tela. Assim, naquele momento, a prática dessa professora, cujo trabalho foi acompanhado no período citado, contrariava o que está exposto no documento governamental sobre a temática, de acordo com o qual "[...] os benefícios da estimulação precoce serão mais efetivos quando o processo for organizado e aplicado de forma gradual, variada e motivadora, seguindo o desenrolar do progresso que a criança for alcançando em seu desenvolvimento" (BRASIL, 1995, p. 16).

No entanto, tal situação decorria do fato de que P2 havia assumido há poucos meses o trabalho com a turma de educação precoce, haja vista que até então sua experiência profissional era com alfabetização no ensino comum. Desse modo, a docente se encontrava 
em processo de (re)construção de identidade profissional com a estimulação precoce. P2 também relatou que, inicialmente, a criança com SPR chorava com frequência, provavelmente por estar, também, em processo de adaptação à nova professora e a seu modo de trabalho, embora já estivessem conseguindo interagir satisfatoriamente com o passar do tempo. A observação participante deu veracidade aos seus relatos:

[...] no começo ela chorava. [...] essa parte que estou tentando trabalhar com ela, a parte de dividir, porque ela foi tratada muito assim, tudo meu, só meu. Ela é uma aluna bem geniosa, tem um gênio bem difícil, assim, mas ela, porém, está conseguindo. Ela não dividia atividade, tudo era só dela, agora pelo menos ela está dividindo. Ela não está mais, assim, fazendo birras quando o colega pega, às vezes, peça ou brinquedo, mas assim é bem complicado ali. Oh! Agora, ela não dá mais, assim, trabalho de chorar. (P2).

Conforme o exposto, para P2, seu maior desafio foi trabalhar a dificuldade da criança com SPR em dividir os objetos ou brinquedos com as demais crianças. Nas sessões de observação participante, essa não aceitação de divisão dos objetos pôde ser presenciada, confirmando a fala da P2 e a relevância que teria, na situação, o diálogo constante entre P1 e P2 para se compreender tal comportamento e como redirecioná-lo adequadamente. Sobre isso, foram feitos, pela pesquisadora, os seguintes registros no diário de campo:

Enquanto a estagiária foi dando as mamadeiras para as crianças que mamam, a professora distribuiu no tatame peças de encaixe para as demais brincarem, inclusive a criança com SPR, mas ela não gostou de dividir os objetos, permanecendo em um canto da sala, mesmo sendo agradada para voltar a participar da brincadeira (Diário de Campo, 02/04/2018).

Eu [estagiária-pesquisadora] e outra criança estávamos sentadas no tatame próximo da criança com SPR, que, aproveitando a proximidade, pegou os brinquedos que tínhamos na mão. Posteriormente, uma outra criança estava brincando com um balanço em forma de cavalo, quando a criança com SPR quis pegar o brinquedo. Não deixei, explicando que não podia fazer isso, que sua colega tinha pegado primeiro e, depois que esta terminasse, ela poderia brincar. A criança com SPR parou no meio da sala emburrada, não se importando com minhas tentativas em agradá-la (Diário de Campo, 03/04/2018).

Quando P2 relatou que já começava a obter resultados positivos, por meio do trabalho desenvolvido com a criança, em relação à divisão dos brinquedos, na observação participante esse feito foi constatado. O seguinte registro em diário de campo corrobora tais avanços:

A professora fez as seguintes atividades: passou fita larga em um bambolê; posteriormente, fixou na parede, explicando para as crianças qual a dinâmica da atividade. Posteriormente, as crianças iam colando bolinhas 
coloridas nesse bambolê, conforme as cores que a professora ia pedindo. A criança com SPR brincou bastante entusiasmada com seus colegas, permanecendo nessa atividade por um bom tempo, até se cansar (Diário de Campo, 27/04/2018).

Pelo engajamento da criança com SPR na realização da brincadeira citada, notou-se que ela apreciou esse momento de descontração, confirmando ser “[...] é verdadeira a ideia popular de que, para criança, brincar é a coisa mais séria do mundo, tão importante para o desenvolvimento quanto comer e dormir" (BRASIL, 2016, p. 159). Já no tocante aos recursos disponibilizados na sala para a estimulação dessa criança com SPR, quando questionada sobre isso, $\mathrm{P} 1 \mathrm{deu}$ as seguintes respostas:

Muito objeto sonoro, objetos coloridos. Como ela já estava começando a sentar, [usava] rolo $^{5}$ e a gente trabalhou muito também com andador. Depois, com os anos passando, o desenvolvimento dela foi ficando bom. A gente começou a trabalhar com andador e muitos livros, todos que foram objetos sonoros e táteis foram trabalhados com ela, [com] muito lúdico. (P1).

Pela fala de P1, esta recorreu a várias estratégias e recursos para o desenvolvimento de suas práticas pedagógicas e, inclusive, dá relevância à ludicidade, como fundamento para o desenvolvimento da criança pequena que precisa de apoio especializado. $\mathrm{O}$ exposto por $\mathrm{P} 1$ só reforça que, de forma deliberada, o papel do professor é oportunizar tais práticas pedagógicas e experiências ao sujeito nesse processo de estimulação precoce, no qual " [...] a ludicidade aparece como pressuposto comum, uma vez que, como mencionado, ela (a ludicidade) não é propriamente ou apenas uma estratégia de trabalho, mas uma característica da infância" (BRASIL, 2016, p. 159). Diante disso, sua atuação como docente encontra ressonância nos dizeres oficiais, no que concerne às funções específicas do professor, a saber:

Este profissional é figura indispensável no planejamento, implantação e implementação dos programas de atendimento especializado e na inclusão das crianças nas creches e nos centros de educação infantil. Na ausência dos demais profissionais da equipe, são facultativas ao professor certas tarefas de avaliação e de orientação atribuídas a eles, desde que receba apoio e supervisão nos aspectos atinentes a outras especialidades da equipe. Além das funções já descritas, competem especificamente ao professor: avaliar as oportunidades educacionais oferecidas à criança por sua família, bem como as práticas e experiências enriquecedoras que possa ter no lar, sem invadir a intimidade da família e respeitando seus valores, a fim de incentivá-la a

\footnotetext{
${ }^{5}$ Nesse caso, rolo se refere a um recurso utilizado para estimulação motora e equilíbrio infantis. Segundo melhor define Aranha (2002, p. 21), "O rolo é feito com manta de espuma, forrada de plástico e revestido com tecido que pode ser retirado para lavar. Pode ter de 20 ou $40 \mathrm{~cm}$ de diâmetro, conforme seja aplicado nas estimulações com os bebês com menos de seis meses e que ainda não se sustentam ou com aqueles a partir de sete meses e que já se mantêm firmes".
} 
participar, de modo efetivo, do processo educacional; acompanhar e avaliar, por meio de estratégias e instrumentos, o desenvolvimento da criança com a participação da família; verificar e sugerir ações em relação à eliminação de barreiras arquitetônicas, atitudinais (mitos, preconceitos e outros) e, principalmente, curriculares; elaborar e executar planos para atendimento pedagógico, individual ou em grupo; incentivar as famílias a utilizar recursos recreativos ou educacionais da comunidade como jardins, parques infantis, creches, pré-escolas, clubes e outros (BRASIL, 2000, 38).

Já a resposta de P2 sobre os recursos pedagógicos utilizados por ela foi a seguinte:

Então! O que eu utilizo na sala? Peça de montar, lápis de cor, a bola; às vezes, bambolê, também com atividade do bambolê, massa de modelar e livros, livrinhos de história, coisa assim. (P2).

Como transcrito anteriormente, embora $\mathrm{P} 2$ tenha mencionado vários recursos utilizados para a estimulação da criança com SPR, pôde-se constatar, pela observação participante, que os recursos usados pela docente foram: peças de encaixe, bola e bambolê. Dos trinta dias de observação, esses materiais foram utilizados separadamente, em dias diferentes, sem propostas de articulação entre si. Pelo menos na forma como conduzia sua atuação, as atividades realizadas em sala por P2 sugeriam a não existência de um planejamento individualizado, que contemplasse as necessidades específicas de desenvolvimento da criança com SPR, inclusive pelo fato de que, por vezes, a estagiária-pesquisadora teve que desempenhar intervenções típicas do papel de docente com a turma de educação precoce. As intervenções de P2, como observadas, ocorriam de forma assistemática e espontaneísta, em desacordo com as recomendações para o processo de estimulação precoce na Educação Infantil, haja vista que, consoante às diretrizes oficiais (2016, p.162),

O brincar, naturalmente, também é meio para alcançar objetivos da estimulação precoce: desenvolvimento da habilidade motora fina; controle postural; desenvolvimento de conceitos; oportunidade de descobrir novas fronteiras de desenvolvimento; ensaio de papéis sociais e ocupacionais; exploração dos sentidos do mundo em que vive; desenvolvimento de habilidades perceptuais e intelectuais; aquisição de linguagem e integração de habilidades cognitivas.

Tal situação evidencia a relevância do docente conhecer os documentos oficiais e diretrizes técnico-pedagógicas que orientam como trabalhar com a estimulação precoce. Percebe-se, também, a necessidade de a instituição privado-filantrópica promover partilhas de conhecimentos entre seus integrantes e tempos-espaços de planejamento coletivo, ofertando formação continuada para esses profissionais e colaboração deles entre si, posto 
prestarem um serviço educacional especializado e complexo. De acordo com Cacheffo e Garms (2013, p. 112),

É função do professor oferecer às crianças pequenas (0-5 anos) uma educação que promova a integração da dimensão cognitiva em relação à dimensão afetiva, embora essas dimensões se alternem em determinadas situações. [...]. O professor é o responsável pelo planejamento das situações de cuidado e educação a serem oferecidas para as crianças, é o mediador das situações de conflitos e cooperação. Portanto, é necessário que possua subsídios teóricos e práticos no que tange ao desenvolvimento infantil, uma vez que são as mudanças qualitativas as propulsoras de sua evolução.

Nesse sentido, por ser a estimulação precoce um processo, não pode haver grandes rupturas quando há troca de um profissional por outro, pois a criança com NEE é a principal prejudicada com esses rompimentos e a inexistência de trabalho colaborativo entre os membros de uma equipe especializada. Na observação participante, não foi presenciada essa interação desejável entre P1 e P2, na forma de colaboração mútua para a estimulação e continuidade das mediações educacionais no tocante à criança com SPR. Tal articulação entre as professoras caberia à instituição promovê-la como eixo fundamental do atendimento especializado.

Por outro ângulo, em relação à acessibilidade, foi verificado que, na instituição visada, a sala onde se dava a oferta de atividades para educação precoce estava organizada de forma a facilitar a locomoção das crianças em seu interior, pois havia tanto aquelas que andavam sem necessidade de auxílio, como outras que necessitavam da assistência de cadeiras de rodas. Por isso, os brinquedos estavam, também, dispostos de forma a facilitar o acesso de acordo com o interesse e uso das crianças, o que revela um ponto positivo em relação às condições institucionais para a mediação pedagógica especializada. Afinal, "O atendimento em estimulação precoce deve ser realizado em espaços físicos adequados ou adaptados às necessidades da criança, contendo mobiliário, material pedagógico e equipamentos apropriados ao trabalho a ser desenvolvido, de acordo com a necessidade da criança" (BRASIL, 1995, p. 22). Nesses termos, concluiu-se que a sala de educação precoce estava organizada adequadamente para que a criança com SPR tivesse liberdade de acesso e movimento no referido espaço.

A partir de todo esse contexto institucional e pedagógico, quando indagadas sobre como avaliavam seu trabalho, quanto ao desenvolvimento da criança com SPR, foram obtidas as seguintes respostas: 
Eu! Assim, ela está uma criança hoje de três anos, ela está uma criança pronta para ser inserida no ensino regular, eu não sei se a família já fez isso, mas ela está pronta, ela é uma criança que vai se desenvolver bem. No início, quando ela chegou, o ensino regular - as creches - não aceitaram ela, devido se alimentar por sonda, só que com o trabalho que foi realizado na escola [especializada], eu creio que ela está pronta. A mãe pode inserir ela no ensino regular, que eu creio que vai dar certo. Um bom trabalho. (P1, grifos nossos).

Então! Como que eu comecei o trabalho agora, e é só começo do ano, até o momento eu acho que o trabalho está sendo bom. Ela está assim, está desenvolvendo bem, até o momento para mim, por enquanto está bom, é que a gente tem ainda o resto do ano todinho, né? (P2, grifos nossos).

De acordo com P1, o trabalho realizado na instituição especializada foi adequado, pois considerava que a criança superara as primeiras barreiras e estava, inclusive, em condições de ser aceita no ensino comum, posto que, nos primeiros anos de vida, fora recusada pelas creches da cidade em virtude de apresentar NEE decorrentes da SPR. Aliás, é importante ressaltar que tal situação ilustra as limitações das instituições de Educação Infantil para englobar serviços da Educação Especial em uma perspectiva inclusiva. Na observação participante, comprovou-se esta afirmação de P1 em relação à possibilidade inclusão da criança com SPR no ensino comum. Isso porque, em um dia, quando a mãe veio pegá-la na instituição, relatou à estagiária e observadora participante desta pesquisa que a menina, em contraturno, seria, finalmente, matriculada na Educação Infantil do ensino comum. Na ocasião, foi feito este registro:

A mãe da criança com SPR veio pegá-la e disse que ia levá-la, pela primeira vez, no período vespertino, para a creche [do ensino comum] [...] (Diário de Campo, 05/04/2018).

Na sua acepção, P2, embora tivesse iniciado com a turma de educação precoce há pouco tempo, acreditava fazer um bom trabalho; porém, na observação, foi possível depreender que suas práticas pedagógicas não condiziam, necessariamente, com os objetivos da estimulação precoce, possivelmente por sua inexperiência nesse trabalho especializado. Há que se alertar, porém, que "quanto maior é o tempo e a intensidade da estimulação inadequada a que a criança estiver sujeita, tanto maiores são a tendência a desenvolver deficiências e a probabilidade de intensificá-las" (BRASIL, 1995, p. 7). Toda e qualquer criança com NEE tem sua especificidade, demandando uma metodologia singular e planejamento educacional individualizado para seu desenvolvimento. Cabe à instituição especializada pensar estratégias, juntamente com o conjunto de profissionais e familiares, para 
atender às singularidades de seu público, sob pena de impactar negativamente na história de vida dessas crianças.

Por fim, quando questionadas sobre como era sua interação com a criança com SPR e desta com os demais colegas da sala, as docentes deram as seguintes respostas:

Então! No começo foi um pouquinho complicado, mas ela é uma criança que se adaptou muito bem e uma criança que tem muita vontade de aprender. Tanto é que todas as atividades propostas na sala ela conseguiu realizar [...]. Eu falo que ela está pronta para o ensino regular, mas é uma criança que eu creio que, daqui mais uns anos, ela não é mais aluna [da instituição especializada] [...], né? (P1, grifos nossos).

P1 reforçou, na entrevista, que, mediante os resultados da estimulação precoce, em algum tempo, não haveria mais necessidade de a aluna frequentar a instituição para suporte especializado. Logo, estaria atingido um dos principais propósitos de um programa como esse. Dito de outro modo, sua fala ratifica a importância dos estímulos pedagogicamente direcionados para o desenvolvimento do sujeito, em especial quando apresenta algum tipo de deficiência ou NEE, desde os primeiros meses de vida, uma vez que "o emprego de programas de estimulação precoce pode prevenir ou atenuar os possíveis atrasos ou defasagens no processo evolutivo infantil” (BRASIL, 1995, p. 7). Já em sua concepção, P2 relatou que:

[...] ela [a criança com SPR] tem uma boa interação, assim, tirando os dias que ela chega ... já vem de casa, às vezes, brava; mas, assim, depois que chega, melhora. É tão boa comigo, como com os colegas. Questão de briga não tem. Ela não é de ficar brigando com o colega. (P2, grifos nossos).

P2 destacou, então, que a criança com NEE, às vezes, chegava à instituição brava e, realmente, sua fala pôde ser evidenciada na observação participante, a partir da qual, em dias diferentes foram realizados os seguintes registros:

A criança com SPR chegou à sala de educação precoce, com sua mãe, que a traz todos os dias. A professora titular da sala foi quem a recebeu, mas ela estava um pouco retraída e se dirigiu a um dos brinquedos que estava no canto da sala. (Diário de Campo, 02/04/2018).

Como a criança com NEE não queria ficar na sala, peguei-a no colo, iniciando uma conversa na tentativa de agradá-la, e fomos guardar sua mochila no armário. (Diário de Campo, 03/04/2018).

A criança com NEE chegou trazida por sua mãe. Como ela não queria ficar, peguei-a no colo, conversando para que mudasse de ideia. Ela permaneceu no meu colo por alguns minutos. Sugeri que pegássemos alguns brinquedos, sendo isso aceito prontamente (Diário de Campo, 04/04/2018). 
Não obstante, para P2, a criança com SPR já interagia bem com os colegas, uma vez que, no início de seu trabalho com ela, essa interação era mais difícil, talvez por causa das características atípicas em seu desenvolvimento físico-orgânico, causadas pela SPR, bem como pela mudança de professora, cujo impacto pode ter repercutido no comportamento da criança, especialmente se se leva em conta a inexperiência da docente com o serviço de estimulação precoce, em um contexto institucional de escassa ou nenhuma colaboração entre as professoras. Ainda assim, em sua avaliação, P2 destacou os avanços relacionados à compreensão da criança sobre a divisão de materiais pedagógicos nas atividades, de modo que estava passava a interagir melhor com a turma e com a professora.

\title{
4.2 Concepções e ações da mãe da criança com SPR sobre estimulação precoce
}

No quesito da percepção dos familiares, a mãe da criança é quem a acompanhava até a instituição. Para ela, o trabalho da estimulação precoce influenciava positivamente no desenvolvimento de sua filha, uma vez que, segundo M:

\begin{abstract}
Desde quando ela começou, ajudou bastante, estimulou ela muito, né? $\mathrm{Na}$ fala também, no comportamento dela, né? Ela desenvolveu bastante na fala, coisa que de uns tempos para cá... Ela não falava, ela está conseguindo, meio enrolado, mas ela consegue, né? E ela está bem, está ótima. Cada dia que passa, assim, ela está superbem, ótima, assim se desenvolvendo bastante. Assim, ela é bem atendida, né? Desde quando ela começou, foi bem cuidada, nunca teve nem uma coisa que prejudicou ela, nem nada. Eu vejo que tudo que é feito ali [na instituição especializada] é com carinho, com amor, com muita atenção. Então, eu acho que é ótimo, que é bom, [...] ela entrou com sete meses, tem uns dois anos... Quando ela estava com sete meses, você colocava ela assim no colchão. Do jeito que você deixava, ela ficava largada. Quem tinha que estar estimulando era eu, que tinha que estar virando ela de lado. Você virava ela de lado, ela ficava; ela não sabia voltar e, depois que ela entrou lá, mudou bastante. Ela se desenvolveu bastante; então, para mim, foi muito bom, tudo ótimo. (M, grifos nossos).
\end{abstract}

Nos relatos da mãe, pôde-se perceber sua satisfação com o processo de estimulação precoce, ofertado pela instituição privado-filantrópica, reforçando a relevância da participação e acompanhamento dos familiares no desenvolvimento da criança com SPR. Por outro lado, é importante que não se sobrecarregue apenas um familiar, em especial as mães/mulheres, em virtude de estereótipos e papéis historicamente atribuídos e projetados ao gênero feminino, como ocorria no caso de M, pois, conforme suas palavras, 
[...] só eu que estou envolvida com ela, levando e buscando, né? E fico dentro de casa com ela, vendo o desenvolvimento dela, né? Não estando, assim, presente, às vezes, lá dentro [da instituição], mas eu participo, né? Porque eu vejo bastante como que ela está, né? Porque eu levo, eu fico sabendo como que está o desenvolvimento dela lá, né? E vejo quando vou buscar ela também. É que tudo é eu, né? Eu participo bastante, né? (M, grifos nossos).

A mãe da criança expôs que sua participação no processo de estimulação era efetiva, pois participava ativamente, tanto no âmbito familiar como na instituição. Seu depoimento salientou a suma importância da "participação direta dos familiares nos atendimentos à criança para assegurar a eficácia do plano individual e sua continuidade no lar” (BRASIL, 1995, p. 21). Dessa maneira, a participação familiar no desenvolvimento da criança com NEE é primordial, haja vista que a estimulação precoce é um processo contínuo, que não se limita somente ao contexto institucional, mas também se prolonga no espaço familiar com ações a serem continuadas. A esse respeito, $\mathrm{M}$ demonstrou seu envolvimento com a situação, na medida em que:

Eu fiz bastante com ela, quando ela fez a cirurgia [em virtude da SPR], né? Que tinha que estar estimulando a fala dela, né? Então, as fonoaudiólogas de Bauru ${ }^{6}$ [cidade do interior paulista], me ensinaram a fazer aquele assim (fez gestos) o "MA" com ela, né? A estimular o som que ela não consegue pronunciar, ensinar ela pronunciar através do fechar e abrir a narina dela, né? Que daí ela consegue emitir o som, daí essa que eu mais fazia com ela, né? Âs vezes, eu ainda faço, quando ela deixa. Aí, também, quando ela estava novinha, eu tive que fazer fisioterapia nela em casa também, né? Eu fiz bastante. (M, grifos nossos).

M evidenciou, portanto, que, mesmo não tendo conhecimentos sistemáticos sobre a estimulação precoce e residindo em cidade no interior do Mato Grosso do Sul, sem maiores recursos, ela continuou em casa os estímulos que os profissionais da saúde a orientaram sobre como fazer com a filha no ambiente familiar. Deacordo com Formiga e Ramos (2016, p. 113), “O papel do profissional consiste em propor que a família se envolva ao máximo no programa de intervenção e que os pais se sintam confiantes em trabalhar com a criança em casa e aprendam também a observar os seus progressos". Na mesma direção, segundo Gualda, Borges e Rodrigues (2013, p. 82),

\footnotetext{
${ }^{6}$ Em Bauru-SP, está localizado o Hospital de Reabilitação de Anomalias Craniofaciais da Universidade de São Paulo, conhecido como Centrinho. Essa instituição é um dos maiores centros de referência em tratamentos craniofaciais de toda a América do Sul, dispondo, portanto, de tratamentos especializados para a SPR de forma gratuita. Por isso, M precisou se deslocar até lá.
} 
Considerando todos esses aspectos, nota-se quão essencial é o papel da família para o desenvolvimento de uma criança, que de acordo com as várias áreas do conhecimento, procuram compreendê-la como um contexto complexo, promotor do desenvolvimento primário, da sobrevivência e socialização.

É preciso enfatizar, contudo, que, para esse papel ser exercido de forma mais profícua, os profissionais especializados que trabalham com crianças com NEE, inclusive os professores da Educação Especial envolvidos com programas de estimulação precoce, devem fornecer instruções bem direcionadas e compreensíveis para os familiares sobre como eles também podem estimular sua criança, garantindo-se a continuidade das ações institucionais no espaço doméstico e familiar. Como já prescrevem os documentos governamentais, "A família tem um papel fundamental para que a criança progrida. Os pais deverão receber apoio e orientação sistemática dos profissionais envolvidos, individualmente ou em grupo, como forma de assegurar a continuidade do trabalho no lar" (BRASIL, 1995, p. 22).

\subsection{Interação entre professoras e a família da criança com SPR}

Quando indagadas sobre como ocorria a interação professora/família, obtiveram-se as seguintes respostas de $\mathrm{P} 1, \mathrm{P} 2$ e de $\mathrm{M}$ :

[...] é uma mãe que corre muito atrás. É uma mãe muito boa, é uma pessoa muito prestativa, é uma pessoa que você, é, propõe uma atividade, ela corre atrás. Então, é uma mãe fácil de lidar, é uma pessoa que sempre vai estar ali, sempre pronta para ajudar a filha. [...]. (P1).

[...] o relacionamento dela comigo é bom. Eu não tenho, assim, não tive problema, até agora. Na reunião, ela sempre vai, todo dia ela está lá. A gente pode estar trocando informação [...]. É um relacionamento bom. (P2).

Ah! É ótimo, né? Para mim, é bom, né? Assim, ela [a professora] sempre fala o que acontece com ela [a filha de M], o que ela faz, né? Ah, ela me explica, aí, o que acontece com a (M diz o nome da criança). Quando eu levo a (M diz o nome da criança) para viajar, também eu relato para ela, né? Então para mim, assim, é bom, né? [...]. (M).

Mediante os dados expostos, P1, P2 e a mãe da criança relataram que a interação entre elas era de um modo rotineiro e colaborativo, pois, sempre que foi solicitada a presença de algum familiar ou responsável nas reuniões institucionais, a mãe atendia prontamente à solicitação e, nesses encontros, algumas dúvidas que porventura surgissem eram esclarecidas e trocadas informações sobre a saúde da criança, suas necessidades específicas, viagens para tratamentos médicos e seus progressos. Na observação participante, pôde-se confirmar essa 
interação existente entre a mãe da criança com SPR e P2, pois, durante todo o período de observação participante, notou-se que a mãe sempre acompanhava a criança. Ela conversava com a professora e, também, com a estagiária da sala, ora contando como foram as consultas da filha, ou até mesmo para desabafar sobre o comportamento desta, o que trazia subsídios para se (re)pensar as intervenções pedagógicas. Nos registros da pesquisadora, destacou-se a seguinte situação:

A criança com SPR chegou na sala no colo de sua mãe, que nos disse que, quando chegou ao portão da instituição, ela começou a fazer birras para não entrar. A mãe nos relatou o ocorrido, mostrando a perna arranhada pela criança com SPR, que tinha feito birra para não ficar na instituição. (Diário de campo, 19/04/2018).

De acordo com Dobrochinski e Parra (2016, p. 06),

Os familiares não só aprendem com os profissionais como contribuem, agregam com suas experiências, partilhando da construção de todo o processo. Com esse envolvimento familiar, o processo de estimulação torna-se mais efetivo e eficaz, garantindo avanços no desenvolvimento e levando a criança a se tornar mais ativa e com maior fortalecimento de sua personalidade, situação familiar e social.

Essa interação entre a professora e $\mathrm{M}$ foi um ponto importante que emergiu nas observações, pois considerou-se a prática benéfica para o desenvolvimento da criança com SPR. Entende-se que, a partir desse intercâmbio, estavam se constituindo conhecimentos práticos de como se trabalhar com tal criança, o que, certamente, era uma necessidade de P2, cujo trabalho também precisava avançar no campo da fundamentação teórico-metodológica no tocante à estimulação precoce e, em particular, no caso de um sujeito com SPR.

\section{Considerações finais}

A partir dos estudos realizados, detectou-se a necessidade de um trabalho colaborativo entre as professoras da instituição de Educação Especial a fim de se evitar ou minimizar rupturas nas práticas pedagógicas das docentes, enquanto integrantes de um programa de estimulação precoce. Ademais, com base no exposto, defende-se que as ações e mediações docentes precisam ter objetivos bem delimitados e planejados para o desenvolvimento das crianças com NEE, como no caso desta com SPR, pois corre-se o risco de se desencadear uma prática que não atenda ou não reconheça as necessidades específicas do sujeito. Assim, é de suma importância que os professores conheçam as orientações legais, as 
diretrizes oficiais e participem de formação continuada sobre estimulação precoce em sua interface com a Educação Especial e outras áreas envolvidas. Nessa direção, reitera-se, ainda, que as propostas de atendimento especializado para crianças pequenas não podem ser desconectadas, também, do direito delas à vivência da Educação Infantil, que incide sobre o mesmo período da estimulação precoce.

Pelos relatos apresentados, entende-se que a instituição teve um papel relevante, apesar das críticas que possam ser feitas ao modo como houve descontinuidades da oferta desse serviço quando se considera a desconexão entre a prática pedagógica de P1 e P2; ao caráter exclusivo do programa, por não estar vinculado, desde o início, à Educação Infantil do sistema público de ensino; e à falta de maior apoio institucional ao trabalho de $\mathrm{P} 2$, como professora iniciante nessa modalidade. Mesmo assim, o processo de estimulação realizado no local obteve efeitos significativos no desenvolvimento da criança com SPR, como em seus avanços na oralidade, interação social, motricidade e autonomia, principalmente quando se observa que esta sequer fora aceita, por suas características físicas e dificuldades alimentares iniciais, em instituições comuns de Educação Infantil, apesar das proposições de uma educação inclusiva no país. Tal situação sugere que ainda permanece uma desarticulação entre os serviços especializados de estimulação precoce, dos quais participa a Educação Especial, e a Educação Infantil, o que tem feito muitas crianças serem encaminhadas, exclusivamente, como única opção, a instituições privado-filantrópicas que suprem essa demanda, pelo menos nos primeiros anos de vida, cerceando as possibilidades de se construir, no sistema comum de ensino, uma Educação Infantil inclusiva pública, estatal, laica, gratuita e disponível a crianças com e sem NEE. Nas palavras de Silva et al. (2017, p. 854),

A ausência da educação precoce na rede pública de ensino do Brasil, infelizmente, ainda é uma realidade. São necessárias políticas públicas e educacionais mais sérias e objetivas para que todas as crianças nascidas prematuras e com necessidades educacionais especiais sejam contempladas.

Por fim, em relação ao caso aqui apresentado, é importante que as professoras, com apoio institucional, sistematizem e fundamentem teoricamente o serviço educacional especializado ofertado, de modo que outras crianças com a mesma condição ontogenética possam ser cada vez mais atendidas em suas necessidades específicas, posto ser a SPR uma condição rara e ainda pouco discutida no cotidiano educacional e na literatura pedagógica. Sua experiência docente e seus conhecimentos acumulados sobre o tema tornam-se, assim, de grande interesse. Ademais, é mister que a instituição, em parceria com a família e vice- 
versa, siga colaborando e apoiando os primeiros anos de ingresso dessa criança na Educação Infantil e nos anos iniciais da escola comum, compartilhando com estes outros espaços seus saberes e fazeres, a fim de que se possa mediar uma práxis educacional cada vez mais inclusiva, articulada e colaborativa.

\section{REFERENCIAS}

ARANHA, Maria Lúcia Azevedo Ribeiro. Desenvolvimento Infantil na creche. 2. ed. São Paulo: Loyola, 2002.

BEZERRA, Giovani Ferreira. Mediação verbal para alunos com deficiência intelectual na Sala de Recursos Multifuncionais: reflexões e (pro)posições, Revista Práxis Educativa, v. 12, n. 3, p. 960-979, 2017. Disponível em:

$<$ https://www.researchgate.net/publication/320286343_Mediacao_verbal_para_alunos_com deficiencia_intelectual_na_Sala_de_Recursos_Multifuncionais_reflexoes_e_proposicoes>. Acesso em: 22 ago. 2018.

BOGDAN, Robert C.; BIKLEN, Sari Knopp. Investigação Qualitativa em educação: uma introdução à teoria e aos métodos. Porto editora LDA. Portugal. 1994. Disponível em: $<$ http://docente.ifrn.edu.br/albinonunes/disciplinas/pesquisa-em-ensino/investigacaoqualitativa >. Acesso em: 20 abr. 2018.

BORGES, Gabriela Silva Braga. Estimulação precoce, trabalho pedagógico e a criança com deficiência na creche. 2016. 172 f. Dissertação (Mestrado em Educação) Universidade Federal de Goiás, Catalão, 2016. Disponível em: <https://repositorio.bc.ufg.br/tede/bitstream/tede/5618/5/Disserta\%C3\%A7\%C3\%A3o\%20$\% 20$ Gabriela\%20Silva\%20Braga\%20Borges\%20-\%202016.pdf >. Acesso em: 16 maio. 2018.

BRASIL. Referencial curricular nacional para a educação infantil: estratégias e orientações para a educação de crianças com necessidades educacionais especiais. Ministério da Educação - Brasília: MEC, 2000. Disponível em <http://portal.mec.gov.br/seb/arquivos/pdf/eduinf_esp_ref.pdf > Acesso em: 30 maio 2020.

BRASIL. Diretrizes Educacionais sobre Estimulação Precoce: o portador de necessidades educativas especiais. Brasília: MEC, SEESP, 1995. Disponível em: $<$ http://www.dominiopublico.gov.br/download/texto/me002557.pdf $>$. Acesso em: 30 maio. 2020.

BRASIL. Diretrizes de estimulação precoce: crianças de zero a 3 anos com atraso no desenvolvimento neuropsicomotor. Brasília: Ministério da Saúde; Secretaria de Atenção à Saúde, 2016. Disponível em: < http://www.abenforj.com.br/site/arquivos/manuais/298\%20Diretrizes-de-estimulacaoprecoce.pdf >. Acesso em: 30 maio. 2020.

CACHEFFO, Viviane Aparecida Ferreira; GARMS, Gilza Maria Zauhy. A afetividade na função do professor de educação infantil. In: CIRÍACO, Klínger Teodoro; BEZERRA, 
Giovani Ferreira (Orgs.). Educação Básica, Formação de Professores e Inclusão. Curitiba: CRV, 2013, p. 107-114.

CARDOSO, Carolina; FERNADES PROCÓPIO, Leandra; MARCOS, Procópio. Estimulação precoce na educação infantil: um estudo bibliométrico. Revista EDaPECI, São Cristóvão, v.17. n. 1, p. 166-186 jan. /abr. 2017. Disponível em: < https://seer.ufs.br/index.php/edapeci/article/view/5964>. Acesso em: 30 maio 2020.

COSTA, Regina Célia Gradowski Farias Da. O estado do conhecimento sobre estimulação precoce no conjunto de teses e dissertações brasileiras no período entre 2000 e 2011. Dissertação (Mestrado em Educação) - Universidade Federal do Paraná, Curitiba, 2013. Disponível em:

<https://acervodigital.ufpr.br/bitstream/handle/1884/33824/R\%20-\%20D\%20\%20REGINA\%20CELIA\%20GRADOWSKI\%20FARIAS\%20DA\%20COSTA.pdf?sequenc $\mathrm{e}=1 \&$ isAllowed $=\mathrm{y}>$. Acesso em: 08 jun. 2018.

DOBROCHINSKI, Sarah Camila Almeida; PARRA, Claudia Regina. A essencialidade da intervenção precoce em crianças com deficiência intelectual. Psicologia.PT, 2016.

Disponível em: <http://www.psicologia.pt/artigos/textos/A0968.pdf>. Acesso em: 22 ago. 2018.

FORMIGA, Cibelle Kayenne Martins Roberto; RAMOS, Bruna Abreu. Programas de Intervenção Precoce: Orientações Gerais e Experiências. Revista Diálogos e Perspectivas em Educação Especial, Marília, v.3, n.2, p. 111-116, jul. - dez. 2016. Disponível em: 〈http://www2.marilia.unesp.br/revistas/index.php/dialogoseperspectivas/article/view/6755 >. Acesso em: 22 ago. 2018

GUALDA, Danielli Silva; BORGES, Laura; RODRIGUES, Roberta Karoline Gonçalves. A participação da família de crianças pré-escolares público alvo da educação especial no processo de escolarização dos filhos. In: DENARI, Fátima Elisabeth. Educação Especial: reflexões sobre o dizer e o fazer. São Carlos; Pedro \& João. 2013, p. 79-100.

GIL, Antonio Carlos. Métodos e técnicas de pesquisa social. 6. ed. São Paulo: Atlas, 2008 .

GOLLO, Cristina; GRAVE, Magali Teresinha Quevedo. Incidência de crianças participantes dos programas de estimulação precoce de cinco Associações de Pais e Amigos dos Excepcionais do Vale do Taquari. Revista Caderno pedagógico, Lajeado, v. 12, n. 1, p. 221-230, 2015. Disponível em:

<http://www.univates.br/revistas/index.php/cadped/article/view/946/934> Acesso em: 05 jun. 2017.

GLAT, Rosana; PLETSCH, Marcia Denise. Inclusão escolar de alunos com necessidades educacionais. 2. ed. Rio de Janeiro: Uerj. 2012.

MACHACÁS, Rúben Luís Faria. Sequência de Pierre Robin. 2015. 52f. Dissertação

(Mestrado Integrado em Medicina Dentária) - Faculdade de Medicina Dentária, Universidade de Lisboa, Lisboa, 2015. Disponível em:

<http://repositorio.ul.pt/bitstream/10451/25829/1/ulfmd02911_tm_Ruben_Machacas.pdf> . Acesso em 19 abr. 2019. 
MÓNICO, Lisete et al. A Observação Participante enquanto metodologia de investigação qualitativa. CIAIQ, v. 3, p. 724-733, 2017. Disponível em:

<https://proceedings.ciaiq.org/index.php/ciaiq2017/article/view/1447/1404>. Acesso em:

31 maio 2020.

NASCIMENTO et al. Programas de intervenção precoce: caracterização de instituições e profissionais. Revista Educação Especial, Santa Maria, v. 31, p. 431 - 446 abr./jun. 2018. Disponível em:

<https://periodicos.ufsm.br/educacaoespecial/article/view/26414>. Acesso em 15 jun.2018.

SATO et al. Sequência de Pierre Robin - Etiopatogenia, Características Clínicas e Formas de Tratamento. Revista Portuguesa de Estomatologia, Medicina Dentária e Cirurgia

Maxilofacial, v 48, n. 3, p.161-164, 2007. Disponível em: <https://ac.elscdn.com/S1646289007701358/1-s2.0-S1646289007701358-main.pdf?_tid=8dda1b2965c9- 45b0-a81ef0c370a2db4b\&acdnat=1540082737 549ecdd6b305a28064c7d89d7dfad4b6>. Acesso em: 18 out. 2018.

SILVA, André Ribeiro et al. Educação precoce: uma revisão integrativa de literatura. Pensar a Prática, Goiânia, v. 20, n. 4, p. 853-863, out./dez. 2017. Disponível em: < https://www.revistas.ufg.br/fef/article/view/44215/pdf >. Acesso em: 30 maio 2020.

TERZAGHI, Marila Alicia; CORIAT Haydée Liliana. Fundamentos e limites da estimulação precoce. Algumas reflexões. Estilos da Clínica, São Paulo, v. 5, n. 8, p.18-23, 2000. Disponível em: 〈 http://pepsic.bvsalud.org/pdf/estic/v5n8/03.pdf〉. Acesso em: 20 abr. 2018.

TULESKI, Silvana Calvo. Vygotski: a construção de uma psicologia marxista. 2. ed. Maringá: Eduem, 2008.

\section{SOBRE OS AUTORES:}

\section{Rosely Vieira dos Santos Martins}

Pedagoga pela Universidade Federal de Mato Grosso do Sul, campus de Naviraí (UFMS/CPNV). E-mail: vieira.rozelyy @ hotmail.com

(iD http://orcid.org/0000-0001-5584-7469

\section{Giovani Ferreira Bezerra}

Doutor em Educação pela Universidade Federal da Grande Dourados (UFGD); Professor da Faculdade de Educação da UFGD. Membro do Grupo de Estudos e Pesquisa em Educação Inclusiva (Gepei). E-mail: gfbezerra@gmail.com

iD http://orcid.org/0000-0002-4710-3897 